\title{
POSSÍVEIS REFLEXÕES SOBRE CONCEPÇÕES DE CORPO/CORPOREIDADE NOS PERSONAGENS DE UMA PEÇA TEATRAL.
}

Janaína Walkiria Brito e Silva

Vinícius Santos

Michele Silva Sacardo

\section{Resumo}

O presente artigo apresenta possíveis reflexões advindas dos resultados de uma pesquisa que teve como objetivo analisar, a partir de aportes filosóficos, a concepção de corpo/corporeidade nos personagens da peça teatral "Os sete gatinhos" de Nelson Rodrigues. Além desse, os objetivos específicos foram: a) Problematizar o tema sobre corpo e corporeidade, por meio de análises filosóficas dos personagens da obra em questão; b) Analisar as principais concepções de corporeidade que, a nosso ver, os personagens da peça Os Sete Gatinhos representam e as contribuições para a Educação Física. Consideramos que este estudo venha contribuir para um melhor entendimento da subjetividade do corpo para os professores de Educação Física, por revelar aspectos do corpo sujeito que podem ser vistos para além dos padrões préestabelecidos de movimento de acordo com os condicionantes alienadores, em que o corpo e sua corporeidade possam ser reinterpretados à luz da concretude da existência humana, havendo uma aceitação e valorização do corpo/corporeidade como algo fundamental para uma existência com significados.

\section{Palavras-Chave}

Corpo/corporeidade; Educação Física.

\section{POSSIBLE REFLECTIONS ABOUT BODY/CORPORALITY CONCEPTIONS IN CHARACTERS OF A PART THEATRICAL.}

Janaína Walkiria Brito e Silva

Vinícius Santos

Michele Silva Sacardo

\begin{abstract}
The present article presents possible reflections of the results of a research that had as objective analyzes, starting from philosophical contributions, the body/corporality conception in the characters of the play " Nelson Rodrigues' seven kittens ". Beyond of that, the specific objectives were: a) to Problematize the theme on body and corporality through the characters' of the work philosophical analyses in subject; b) to Analyze the main corporality conceptions that, to ours to see, the characters of the piece The Seven Kittens act and the contributions for the physical education. We considered that this study comes to contribute for a better understanding of the subjectivity of the body for the physical education teachers, for revealing aspects of the subject body that can be seen for besides the established patterns of movement in agreement with the alienation, in that the body and his/her corporality can be interpreters to the light of the concrete of the human existence, having an acceptance and valorization of the body/ corporality as something fundamental for an existence with meanings.
\end{abstract}

\section{Key-Words}

Body/ corporality; Physical Education. 


\section{Introdução}

O presente artigo apresenta possíveis reflexões advindas dos resultados de uma pesquisa que teve como objetivo analisar, a partir de aportes filosóficos, a concepção de corpo/corporeidade nos personagens da peça teatral "Os sete gatinhos" de Nelson Rodrigues. Além desse, os objetivos específicos foram:

a) Problematizar o tema sobre corpo e corporeidade, por meio de análises filosóficas dos personagens da obra em questão.

b) Analisar as principais concepções de corporeidade que, a nosso ver, os personagens da peça Os Sete Gatinhos representam e suas contribuições para a Educação Física.

Tal preocupação surgiu pelo fato de não ter havido estudos na Educação Física que analisassem o corpo/corporeidade em personagens da literatura, e porque os discursos de poder são produzidos permanentemente entorno, na superfície e no interior do corpo, e a área da Educação Física tem adotado, na maioria das vezes, o corpo como meio e fim da sua prática, em qualquer segmento que atue.

Alem disso, observamos ainda que os temas sobre "o corpo e a corporeidade" e suas relações com a dramaturgia brasileira têm ficado à sombra nas pesquisas teóricas desenvolvidas dentro da área de Educação Física. Por esta razão, nossa preocupação, parte do pressuposto que, a partir de uma análise detalhada dos personagens, poderemos estabelecer uma análise concreta das atitudes comportamentais dos mesmos, que possam vir a esclarecer sobre temas como a repressão sexual, o patriarcalismo, realidade social, de tal forma que:

[...] não há como analisar o indivíduo sem remetê-lo ao grupo a que ele pertence, à sua classe social. A ação grupal só pode ser compreendida dentro de uma perspectiva histórico social que leve em consideração as determinações econômicas, institucionais e ideológicas da sociedade. Portanto qualquer grupo tem a função histórica de manter ou transformar as relações sociais. (MARCELLINO, 1988, p. 80)

Nessa linha de pensamento Gonçalvez (1997), relatou sobre o corpo na vida cotidiana, onde realiza uma crítica à sociedade industrial e contemporânea e busca descrever os antecedentes históricos das relações do homem com a sua corporalidade. Relatou ainda, a problemática do homem e sua corporeidade no pensamento filosófico, aprofundando seu estudo nas obras dos filósofos Marx, Merleau-Ponty, realizando reflexões sobre o homem, sua realidade social e a questão da corporalidade e do movimento. Aquele autor concluiu, a existência de uma subordinação das ciências que contribuem para a reflexão filosófica, 
não minimizando a importância dos conhecimentos científicos da Biomecânica, Fisiologia, da Aprendizagem Motora, bem como as ciências humanas, como a Psicologia e Sociologia. E, que a reflexão filosófica de nenhum modo substitui esses conhecimentos, mas, sim, permitem ao professor de Educação Física redimensioná-los e integrá-los no ato educativo, a partir de uma concepção de homem e mundo que não reduza o movimento em sua realização concreta, a uma explicação parcializadora, mas que busque compreender o seu sentido de forma sistemática.

Já Moreira (1995), propõe uma produção que percorra a teoria e prática dessa forma, a reflexão e a experiência corporal são investigadas na intencionalidade perspectival e as interpretações resultantes, remetem-nos ao binômio processo-projeto educativo, e afirma que os profissionais da motricidade humana (Educação Física) têm diante de si, uma opção de mudança de paradigma no trato com o fenômeno corporeidade, abandonando o mecanismo tradicional e aventurando-se na descoberta de novas trilhas que poderão um dia estar tatuadas no corpo vivido.

No entanto, Soares (2001, 2002), analisou a racionalização burguesa expressa na formulação da ginástica cientifica. No livro "Educação Física: raízes européias e Brasil”, a autora aborda o pensamento médicohigienista na Europa (1850-1930) e o discurso disciplinador e moral de Rui Barbosa e Fernando Azevedo, no Brasil. Na obra "Imagens da Educação do corpo", analisou a ginástica francesa (Amoros e Demeny) no contexto artístico/circense do século XIX, e concluiu que a ginástica, como estratégia de controle das praticas corporais que se manifestaram nas ruas, festas e jogos populares, é modelo técnico de educação do corpo, que potencializaram as ações de modelagem e adestramento, ensinando o individuo, pelo corpo e no corpo, a ser um disciplinador de si mesmo.

Nesta perspectiva, Michael Foucault, pensador e epistemólogo francês, contribuiu para o movimento antipsiquiátrico e antipedagógico. Utilizamos como fontes subsidiadoras, suas obras intituladas Microfísica do Poder de (2001) e Vigiar e Punir (1999). Enfocamos, a forma pela qual este autor analisou o corpo como dominado pelo poder que em qualquer sociedade, o corpo está preso no interior de poderes muito apertados, que lhe impõem limitações, proibições e ou obrigações, e esta perspectiva, foi o ponto do qual nós nos aponhamos para análise e interpretações das concepções de corporeidade dos personagens da peça.

Na sua obra Vigiar e Punir (1999) Foucault descreveu sobre os corpos dóceis, e o surgimento desta teoria, remete-se aos séculos XVII e XVIII, e foi por meio da disciplina dos corpos que os mesmos tornar-se-iam 
submissos, não significando que antes não houvesse disciplina, e nesse momento tornou-se, forma geral de dominação, exercida em diversos espaços: nos colégios, nos hospitais, na organização militar, na medicalização da sexualidade, nas oficinas, na família, e relata que nesses locais, havia o controle do espaço do tempo dos movimentos, sob um olhar vigilante que é introjetado no indivíduo. Foucault define essa estrutura como uma micromecânica do poder, advinda da classe burguesa emergente, a partir do fim do século XVI e início do século XVII, o que exigiu formas de disciplinização para excluir os incapazes e inúteis para o trabalho.

[...] A burguesia compreende completamente que uma nova legislação ou uma nova constituição não seriam suficientes para garantir sua hegemonia; ela compreende que deve inventar uma nova tecnologia que assegurará a irrigação dos efeitos do poder por todo corpo social, até mesmo em suas menores partículas. [...] (FOUCAULT, 2001, p. 218)

Portanto, podemos retratar essa relação como um controle desse corpo, para a manutenção dessa hegemonia do poder capitalista representado pela classe burguesa, uma vez que a temática central de Michael Foucault consiste na questão do poder nas sociedades capitalistas. E de acordo com o nosso estudo, enfatizamos o exercício do poder nas instituições escola, família e igreja. E entendemos que esse poder, caracterizou-se como uma nova tecnologia que se concretiza através da disciplina aplicada sobre os corpos.

Foucault (1999), ao retratar a submissão do corpo a disciplina, apresenta que esta trata o corpo em massa, como se fosse uma unidade indissociável, exercendo sobre ele uma coerção, mediante movimentos, gestos, atitudes, um poder infinitesimal sobre o corpo ativo. Portanto isso é uma coerção ininterrupta, constante que ajusta o corpo no seu tempo, espaço e nos seus movimentos, permitindo o controle minucioso do corpo.

[...] A disciplina fabrica assim corpos submissos e exercitados, "corpos dóceis". A disciplina aumenta as forças do corpo (em termos econômicos de utilidade) e diminui essas mesmas forças (em termos políticos de obediência). Em uma palavra: ela dissocia o poder do corpo, [...] (FOUCAULT, 1999, p. 119)

De fato, a questão de disciplina na concepção de Michael Foucault, vem de uma maior sistematização dos aparelhos e instituição desde a ascensão do sistema capitalista, mas antes mesmo dessa determinada ideologia econômica, o corpo já vem sendo submetido a uma vigilância para aumentar sua eficácia em relação ao poder. Assim, buscamos nesta concepção explicitada por Foucault (1999), subsídios fazer uma interpretação da corporeidade construída na peça Os Sete Gatinhos. 
Em Michael Foucault o corpo é submetido a um poder controlador e dominante, que está em constante vigília por outros corpos, por meio de aparelhos e instituições. Pelo que foi exposto, compreende-se, que ao longo de sua história, o homem foi submetido a métodos violentos, a negar a sua natureza existencial e a encará-la como algo ruim que precisava ser dominado.

Assim, considerando a complexidade e as contradições de cada personagem, buscamos refletir e compreender em que medida esses personagens podem apontar a dimensão de um corpo que, em sua expressividade, consiga superar (ou burlar) as regras sociais moralmente impostas, como também, conhecer quais elementos encontrados nesses personagens pode vir a reproduzir a reificação social, corporalmente representada.

Contudo, consideramos que este estudo venha contribuir para um melhor entendimento da subjetividade do corpo para os professores de Educação Física, por revelar aspectos do corpo sujeito que podem ser vistos para além dos padrões pré-estabelecidos de movimento de acordo com os condicionantes alienadores, em que o corpo e sua corporeidade possam ser reinterpretados à luz da concretude da existência humana, havendo uma aceitação e valorização do corpo/corporeidade como algo fundamental para uma existência com significados.

\section{Metodologia}

O estudo caracterizou-se por meio de pesquisa bibliográfica por envolver leitura, seleção e registro de literatura de interesse para o estudo proposto.

A peça Os Sete Gatinhos de Nelson Rodrigues, foi descrita no livro "Nelson Rodrigues: Teatro Completo”, organizado e introduzido por Sábato Magaldi em 1985. Por meio deste livro, realizamos a leitura completa da peça em seus atos e quadros. Posteriormente, como instrumento de coleta de dados, foi utilizado uma ficha/roteiro no registro de informações referentes à peça Os Sete Gatinhos, que continha os seguintes itens: autor; título; principais concepções de corporeidade identificadas; problemas sociais e corporais privilegiados. Foram descritas, apenas as cenas que estavam direcionadas a questão do corpo/corporeidade.

A análise dos dados neste estudo caracterizou-se como qualitativa por analisar o conteúdo e interpretar o discurso dos personagens. Para tanto, por uma melhor compreensão de corpo/corporeidade nos 
personagens desta obra literária, foi realizada uma discussão histórico-filosófica do corpo a partir dos escritos de Foucault (1999 e 2001), que aborda o poder exercido pelas sociedades capitalistas em instituições - família, igreja, escola - as quais delimitamos verificar neste estudo.

\section{Possíveis reflexões sobre corpo/corporeidade identificados nos personagens.}

A peça foi colocada em cartaz em 1958, baseando-se em uma realidade social concreta, sendo caracterizada por comédia de costumes, a que nos torna possível associá-la a uma sociedade comercial, por esta ser originada do contexto capitalista. Ao citar essa sociedade comercial, recorremos a Foucault (1999) para exemplificá-la, onde o consumo leva o indivíduo a se tornar átomo fictício representando a sociedade de forma ideológica, mas também é uma realidade que caracteriza a tecnologia específica de poder denominada nesse contexto de disciplina. Poder que exclui, reprime, recalca, abstrai,mascara e esconde, não trazendo apenas essas características negativas para o indivíduo, então este poder, este mecanismo seria vulnerável. O indivíduo apesar de ser reprimido, goza de certa relação de prazer. A sociedade comercial apesar de ser controladora, permite certas regalias, e apesar desse individuo ser um átomo fictício de uma ideologia, esta produz realidade, a partir disso, o individuo se faz presente nessa perspectiva.

Sendo assim, Magaldi (1985), descreveu que Nelson ao definir as características do grupo familiar, criou a família com objetividade realista, onde as quatro filhas prostituíram-se, sendo essas: Aurora que supostamente era a mais velha e trabalhava em um Instituto que não a remunerava de forma suficiente, para que pudesse adquirir o enxoval da irmã mais nova Silene; Arlete, possuía característica de homossexualismo e utilizava-o como refúgio, pela aversão ao universo masculino; Débora era aliciadora de mulheres para homens velhos; Ilda era a mais calada possuía poder mediúnico; e, também a mãe com uma figura patética da "Gorda", confinada numa existência imanente, e contrabalanceando o desinteresse sexual do marido, enchendo as parede do banheiro com pornografias. E, ainda Noronha o patriarca da família, proclama a infinita miséria da família ao falar que todos eles eram canalhas. Por tanto:

Sem o propósito de realizar uma análise de caráter social ou de fundo sociológico, Nelson mostra o substrato da ordem capitalista como condicionante da miséria ética e financeira daquela família. Sua tendência, de fato, é a de unir esses dados transitórios e removíeis a uma falha intrínseca da natureza humana. (MAGALDI, 1985, p. 35)

Sobre o aspecto da repressão corporal presente no grupo familiar, detectamos, mecanismos ideológicos como o capitalismo e o cristianismo, em termos, isso não foi abordado no transcorrer da peça de forma 
enfática, mas influenciou as manifestações de corporeidade, ficando evidente o patriarcalismo, e a questão mística, como forma de poder sobre os corpos dos personagens.

Nelson Rodrigues criou uma concepção real da sociedade, reduzida dentro da relação desse grupo, onde os corpos, desses personagens relacionaram-se, isso exemplifica a teoria de poder sobre o corpo, observado por Foucault, que retrata a submissão dos corpos sobre os outros, em uma dimensão reduzida ao próprio corpo, evidenciando assim a disciplina como um tipo de organização sistemática, que se da à forma de dominação. A partir disso, Walhausen apud Foucault (1999), comenta a relação de poder na construção dos indivíduos pela disciplinização dos corpos.

[...] A disciplina "fabrica" indivíduos; ela é a técnica específica de um poder que toma os indivíduos ao mesmo tempo como objetos e como instrumentos de seu exercício. Não é um poder triunfante que, a partir de seu próprio excesso, pode-se fiar em seu super poderio; é um poder modesto desconfiado, que funciona a modo de uma economia calculada, mas permanente (WALHAUSEN apud FOUCAULT, 1999, p. 143)

De modo geral, foram identificados nos personagens concepções de corpo/corporeidade que ainda se sustentam na sociedade atual fazendo parte da vida das pessoas. Além disso, tentou-se refletir sobre o discurso do poder no corpo.

Assim, detectamos que existem nos personagens as seguintes concepções de corpo/corporeidade:

- A repressão corporal através da prostituição, do misticismo, da educação familiar e escolar.

- O corpo sedutor como sinônimo de beleza e,

- O corpo estereotipado pela concepção de beleza feminina.

Por tudo isso se faz necessário, enfatizarmos a contribuição dessas concepções que foram detectados nos personagens da peça Os Sete Gatinhos de Nelson Rodrigues de 1958, que nesse período, já retratava valores sobre o corpo que atualmente são privilegiados pela sociedade do consumo: o padrão de beleza, o corpo mercadoria que vale pelo que apresenta enquanto força de trabalho, seja em empresas, na indústria do sexo que é tão difundida pelos meios de mídia atuais que eleva o corpo/corporeidade a um fim em si mesmo, como fez o Patriarca da família Noronha ao criar um bordel na sua casa e utilizar dos corpos das filhas como objeto lucrativo. 
Sobre a importância que se dá ao misticismo como determinante de um modelo corporal a ser seguido, que desde o período mítico da história houve a necessidade do corpo em se ligar a algo sobrenatural, como meio e fim para explicar acontecimentos da vida.

Mais ainda, sobre o corpo na instituição familiar e escolar percebe-se uma similitude por adotarem padrões de comportamento por meio da repressão corporal, submetendo o corpo a regras moralmente impostas, e que devem ser assimiladas para uma melhor inserção social, como nos lembra os estudos de Foucault (1999).

\section{Considerações Finais}

Faz-se importante mencionar, que algumas considerações tecidas, não podem ser compreendidas como conclusões definitivas, mas que são necessárias e permitem que se possa continuar refletindo em estudos futuros, como também, nas distintas concepções de corpo/corporeidade presentes na atual sociedade contemporânea.

De fato, a Educação Física ao apropriar-se do corpo como finalidade da sua atuação na sociedade, se apega de algumas concepções apresentadas na peça, pois este corpo não esta desassociado do seu contexto sócio-cultural. Pois, observamos constantemente na sociedade atual, que a questão da beleza corporal - extremamente valorizada pela indústria cultural - tem fomentado o consumo desenfreado de meios, cuja finalidade única, tem sido molda-se e/ou enquadrar-se num padrão corporal estabelecido como o único a ser aceito por todos, não importando quem seja o indivíduo.

A busca pelas concepções de corpo/corporeidade nos personagens que foram submetidos ao poder foi o que se buscou no decorrer deste estudo. Acreditamos que, ao discutir, refletir e buscar concretamente progredir na dimensão da corporeidade avançamos de certa forma, para uma possível resposta para a problemática que originou esta reflexão:

Quais elementos encontrados nesses personagens que podem vir a reproduzir a reificação social, corporalmente representada? E em que medida, esses personagens podem apontar a dimensão de um corpo que, consiga superar as regras moralmente impostas, que são submetidas na relação de poder sobre o corpo? 
Sobre a primeira pergunta, entendemos que esses elementos, voltam-se para uma preocupação com aspectos de moral, com uma aparentável estrutura familiar que possui horários e rotinas sob a tutela do chefe de família, com uma esposa que enxuga os pratos representando a boa e fiel esposa e as filhas submissas ao pai que impõe horários este com o intuito de guardar a castidade da filha mais nova que apresenta um corpo virgem e, a presença do misticismo introjetado na família.

Ao que concerne ao segundo questionamento, supomos a desvinculação dos padrões morais, quando o pai cria um bordel na sua casa submetendo as cinco filhas e a própria esposa a prostituição, devido a "des"santificação do corpo casto da filha mais nova. A obscenidade retratada na parede do banheiro por uma dona de casa, há presença do lesbianismo e por o negligenciamento de crimes como o parricídio que no decorrer da peça ocorrem sem a menor preocupação do fim que será dado aquele corpo e menos ainda aos que cometeram o crime.

Há de se considerar a relação de sujeição dos corpos no inicio da peça, para a manutenção dessa normatização da sociedade, até chega ao ponto da sua sublevação desses corpos contra tal sujeição principalmente na figura do pai, onde ocorre a superação do universo moralista. Apesar desse corpo se revelar no contex to da peça, há todo um aparato da estrutura social para conter essa revolta corporal para continuar a manutenção da normatização, como ressaltou Foucault(1999), que estamos na sociedade do professor- juiz, do médico-juiz e do educador-juiz e do assistente social-juiz, todos fazem reinar a universalidade do normativo; e cada um no ponto que se encontra, ai submete o corpo, os gestos, os comportamentos, as condutas, as aptidões, os desempenhos. O que nos permitiu relatar, que a tecitura carcerária da sociedade realiza ao mesmo tempo as captações reais do corpo e sua perpétua observação.

Por tudo isso, esperamos que a reflexão trazida neste artigo se abra em perspectivas de continuidade e indagações, gerando novos saberes e, conseqüentemente, novos caminhos sobre a discussão corpo/corporeidade. Para isso, o diálogo e a vivência sobre o corpo adquirem um caráter de recusa à submissão que a estrutura de produção impõe aos indivíduos; que os seres humanos não se contentem em apenas adquirir hábitos, mas que se desvinculem dos modelos, das culpabilidades, das marcas que a racionalidade inscreveu nos corpos e que se vivenciem a sua corporeidade real em toda a sua dimensão. A expectativa é que os resultados deste estudo se revertam em subsídios que orientem profissionais da área da Educação Física que trabalham com o corpo/corporeidade, em uma nova perspectiva críticoreflexivo, permitindo a eles uma visão ampliada sobre a dimensão humana, e pela importância de discuti- 
la numa perspectiva que inclua a diversidade humana e o respeito as individualidades de cada sujeito, seja em sua atuação pedagógica, lúdica e esportiva.

\section{Referências}

FOUCAULT, M. Microfísica do poder. 16. ed. Rio de Janeiro: Graal, 2001.

.Vigiar e punir. 19. ed. Petrópolis: Vozes, 1999.

GONÇALVES, M. A. S. Sentir, pensar, agir. 2. ed. Campinas: Papirus,1997.

MAGALDI, S. Nelson Rodrigues: teatro completo. Rio de Janeiro: Nova Fronteira, 1985.

SOARES, C. L. Imagens da educação do corpo. 2. ed. rev. Campinas: Autores Associados, 2002. . Educação Física: raizes européias e Brasil. $2^{\mathrm{a}}$ ed. rev - Campinas, SP: Autores associados, 2001.

MOREIRA, W. W. (Org.). Corpo presente. Campinas: Papirus, 1995. 


\section{Michele Silva Sacardo}

Docente da Universidade Estadual de Goiás (UEG).

Doutoranda do Programa de Pós Graduaçao em Educação da Universidade Federal de São Carlos (UFSCar)

mi_sacardo@yahoo.com.br

Janaína Walkiria Brito e Silva

Licenciada em Educação Física pela Universidade Estadual de Goiás (UEG)

anajeduca@hotmail.com

\section{Vinícius Santos}

Licenciado em Educação Física pela Universidade Estadual de Goiás (UEG)

vinimsatos@hotmail.com 